\section{Military Technical College Kobry El-Kobbah, Cairo, Egypt}

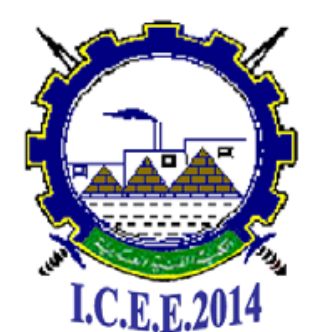

$7^{\text {th }}$ International Conference

on

Chemical \& Environmental Engineering

27 - 29 May, 2014.

\title{
ENMA-4 \\ Effect of Nano-Sized Barium Ferrite Catalyston Ballistic Properties of Composite Propellants
}

\author{
M. I. Gendy ${ }^{*}$ M. k. Hadhood* and M. A. Radwan ${ }^{* *}$
}

\begin{abstract}
Using different ammonium perchlorate (AP) resources even with the same particle size distribution and the same physical and chemical characteristics have some effect on the ballistic performance of aluminized composite solid rocket propellant (Al-CSRP).The main goal of this paper is to retain the optimum characteristics performance of (CSRP) formulations after changing the AP resources either by adapting the particle size distribution of the new AP particles or by adding a catalyst. Effect of changing particle size distribution for the new source ofAP on the ballistic characteristic of (Al-CSRP) was studied in this paper but no significant effect on the goal of this work was obtained. Three burning rate modifiers (BRM) (catalysts) were added separately on the prepared (Al-CSRP) formulations to study their effect on the performance and the ballistic characteristics of these formulations. Nanosized Barium Ferrite (BF) catalyst was able to retain and recover the required ballistic characteristics of CSRP formulation containing the newAP resources, and hence the aim of this work was achieved. Thermal analysis studies were performed on the different types of AP and also on mixtures of AP with different BRM to find the optimum weight percentage of added catalyst. The required weight percentage of nano-sized BF which achieves the goal of this work was found to be $0.05-0.07 \%$ basedon the CSRP formulation mass.
\end{abstract}

\section{Keywords:}

Composite solid rocket propellant, Burning rate modifiers, Ammonium perchlorate and Barium Ferrite.

\footnotetext{
** $\quad$ Egyptian Armed Forces

** British University in Egypt (BUE)
} 


\section{Material}

All the chemicals used in this work are: hydroxyl terminated poly-butadiene(HTPB), hexamethylenediisocyanate (HMDI), di-octyleazelate (DOZ), MT-4, aluminum powder (Al), ammonium perchlorate (AP), ferric oxide $\left(\mathrm{Fe}_{2} \mathrm{O}_{3}\right)$, copper chromite(CCr), barium ferrite(BF).

\section{Introduction}

It was found that adding different types of burning rate modifiers with the same weight percentage on definite chemical compositions have showed also markedly effect on the performance and burning rate of the tested formulations $(1,3)$. The composite propellant formulation studied based on HTPB ("nominal formulation") with the ingredients primarily consisting of 400 and $10 \mu \mathrm{m}$ AP particles.Transition metal [Mn(II), Fe(II), Fe(III), Co.(II), $\mathrm{Ni}(\mathrm{II}), \mathrm{Cu}(\mathrm{II})$ and Zn(II)] salts of 5-nitro-2,4-dihydro-3H-1,2,4-triaole-3-one (NTO) have been incorporated as ballistic modifiers in composite solid propellants (CSPs) of hydroxyl terminated polybutadiene (HTPB) (2,5).Nano-aluminum particles of $50 \mathrm{~nm}$ size are added to composite solid propellants based on AP and hydroxyl-terminated poly-butadiene binder that exhibit plateau burning rate trends and those including burning rate catalysts $(3,13)$. A very important note is the care when using solid accelerators because they have the tendency to migrate through the propellant mass during aging $(4,14)$. Thermal analysis techniques such as DSC and TGA were employed successfully to evaluate the thermal characteristics of CSRP and to examine the performance of these formulations $(5,8,10)$.

\section{Experimental}

The most commonly used types of composite propellants consist mainly of polyurethane binder based on hydroxyl terminated polybutdiene (HTPB), ammonium perchlorate (AP) as an oxidizer, aluminum powder (Al) as metallic fuel and some processing and ballistic additives. In this research, we study the effect of changing the source of AP production on the thermal behavior of AP and the HTBP - CSRP based on it, then the ways for improving the AP thermal behavior and the ways for obtaining the same behavior of different sources.

\subsection{Preparations of composite rocket propellant formulations}

The main objective of this work is divided into three main parts, full analysis and characterization of already given and newsource of AP, Thermal analysis of both types of AP then thermal analysis of new source of AP with different burning rate modifiers. Preparation of propellant samples through studying the main effective parameters such as AP type, different distribution of AP particle size and the role of burning rate modifiers. The binder used in this work was HTPB pre polymer of $0.85 \mathrm{mg}$ equivalent $\mathrm{OH} / \mathrm{g}$ HTPB with DOZ as plasticizer and MAT4 as bonding agent. The pre polymer, bonding agent and the plasticizer were mixed together at $50-60^{\circ} \mathrm{C}$ then solid ingredients were added in portions and thoroughly mixing was continued for 30 minutes. At the end of mixing process, the curing agent HMDI of $11.9 \mathrm{mg}$ equivalent NCO/g HMDI was added by certain amount which keeps the NCO/OH ratio as 0.7 and mixing was carried out for relatively short time. Special degassing unit was employed to get rid of any air bubbles before slurry casting in special moulds for different measurements. Finally, the prepared formulations were cured at about $60^{\circ} \mathrm{C}$ for two weeks (14).The work was run through the following stages:

(1) The analysis and characterization of both ammonium perchlorate throughout the following scheme:

(a) Complete chemical and physical analysis of both types of ammonium perchlorate.

(b) Application of the useful instrumental analysis devices such as FTIR, SEM, DSC and TGA for differentiation between both types of AP. 
(c) Using thermal analysis techniques to explain the effect of burning rate modifiers on the new source of ammonium perchlorate.

(2) Preparation of the new propellant sample during the following phases:

(a) Preparation of two mixes with the same chemical composition and particle size distribution of AP using both types of AP.

(b) Study the effect of different types of the burning rate modifiers.

(c) Apply the testing of the propellant samples such as mechanical properties, hardness, density, and then the ballistic performance.

(d) Study the effect ofAP type on the propellant samples.

Using different sources of AP ( old and new) in conventional CSRP with composition AP/AL (69/17) as preliminary mix for two mixes illustrated in table (3.1) To determine Physical, Chemical, Mechanical and Ballistic properties to obtain the differences.

Table (3.1) Mixes for comparison between old and new AP

\begin{tabular}{|c|c|c|c|c|c|c|}
\hline Mix & Binder & \multicolumn{3}{|c|}{ Oxidizer AP \% } & Metallic fuel & Catalyst \\
\cline { 3 - 5 } No & \% & $\mathbf{4 0 0} \boldsymbol{\mu}$ & $\mathbf{2 0 0} \boldsymbol{\mu}$ & $\mathbf{7 - 1 1} \boldsymbol{\mu}$ & Al \% & $\mathbf{0 . 0 6 \%}$ \\
\hline 1(old) & 14 & 40 & 15 & 14 & 17 & ------- \\
\hline 2(new) & 14 & 40 & 15 & 14 & 17 & ------- \\
\hline
\end{tabular}

Study the effect of new source AP different distribution on the propellant sample using the new source of AP in conventional CSRP, with composition AP/AL (69/17) for three mixes with different particle size distribution of AP, based on increasing the percentage of fine AP grade by decreasing the percentage of medium and course AP grades as illustrated in table (3.2), to determine Physical, Chemical, Mechanical and Ballistic properties.

Table (3.2) Mixes of different distribution percentage of new AP

\begin{tabular}{|c|c|c|c|c|c|c|}
\hline Mix & Binder & \multicolumn{3}{|c|}{ Oxidizer AP \% } & Metallic fuel & Catalyst \\
\cline { 3 - 5 } No & \% & $\mathbf{4 0 0} \boldsymbol{\mu}$ & $\mathbf{2 0 0} \boldsymbol{\mu}$ & $\mathbf{7 - 1 1} \boldsymbol{\mu}$ & Al \% & $\mathbf{0 . 0 6 \%}$ \\
\hline 3(new) & 14 & 37 & 15 & 17 & 17 & ------- \\
\hline 4(new) & 14 & 40 & 12 & 17 & 17 & ------- \\
\hline 5(new) & 14 & 35 & 15 & 19 & 17 & ------- \\
\hline
\end{tabular}

To investigate the role of different types of burning rate modifiers on propellant samples Preparation of three samples based on using three different types of BRM with the same minor percentage to figure out increase of ballistic characteristics of the propellant samples as shown in table (3.3).

Table (3.3) Mixes with different types of B.R.M

\begin{tabular}{|c|c|c|c|c|c|c|}
\hline Mix & Binder & \multicolumn{3}{|c|}{ Oxidizer AP \% } & Metallic fuel & Catalyst \\
$\mathbf{N o}$ & $\mathbf{\%}$ & $\mathbf{4 0 0} \boldsymbol{\mu}$ & $\mathbf{2 0 0} \boldsymbol{\mu}$ & $\mathbf{7 - 1 1} \boldsymbol{\mu}$ & $\mathbf{A l}$ & $\mathbf{0 . 0 6 \%}$ \\
\hline 6(new) & 14 & 40 & 15 & 14 & 17 & $\mathrm{Fe}_{2} \mathrm{O}_{3}$ \\
\hline 7(new) & 14 & 40 & 15 & 14 & 17 & $\mathrm{CCr}$ \\
\hline 8(new) & 14 & 40 & 15 & 14 & 17 & $\mathrm{BaFe}_{12} \mathrm{O}_{19}$ \\
\hline 9(new) & 14 & 40 & 15 & 14 & 17 & T.C.P \\
\hline
\end{tabular}




\subsection{Thermal analysis of AP by DSC- TG}

The thermal analytical measurements (TAM) can describe the materials phase changes with the enthalpy changes accompanying them. Therefore, their thermal behavior can be investigated under these phases by the accurate analysis of the thermo-grams belonging to each ingredient. Thermal analysis performed by TA instrument (model SDTQ 600) simultaneous TGA-DSC thermo gravimetric analyzer. The analysis were conducted for a total sample mass of $16.0 \pm 0.4 \mathrm{mg}$. A known amount of sample was loaded and evenly spread on the alumina micro crucible. The samples were heated under nitrogen flow $\left(100 \mathrm{ml} \mathrm{min}^{-1}\right)$ from 50 to $550^{\circ} \mathrm{C}$, at $5^{\circ} \mathrm{C} / \mathrm{min}$.TGA, DSC and/or DTA techniques is hoped to be deeply help in the combustion properties evaluations through the direct application of their results at the propellant combustion zone. That will be applied by the direct handling of their digital data results to calculate their decomposition characteristic (kinetic) parameters.

\subsection{Measurement of ballistic performance parameters}

The performance parameters of the prepared propellant formulations as burning rate, specific impulse and characteristic exhaust velocity were measured using standard two inch testing rocket motor provided with nozzle of $7.3 \mathrm{~mm}$ throat area diameter which means certain operating pressure and certain burning rate for each formulation.

\section{Results}

\subsection{Results of DSC-TGA for old and new AP (200 $\mathrm{\mu m})$ crystals}

The obtained results for DSC-TGA for the old and new AP crystals of average particle size $(200 \mu \mathrm{m})$ are shown in figures (4.1 and 4.2) respectively.

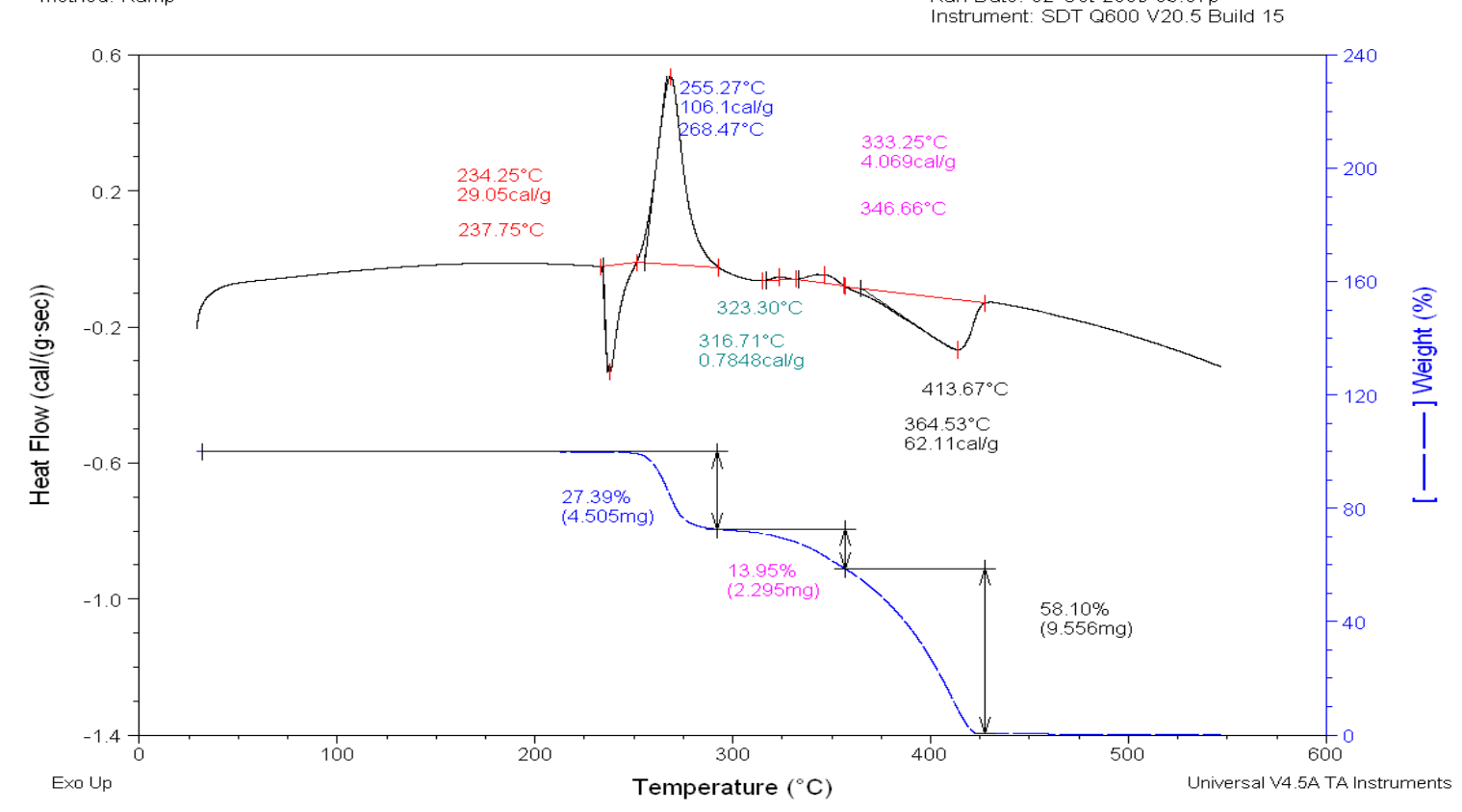

Fig. (4.1) DSC-TGA for AP old source 


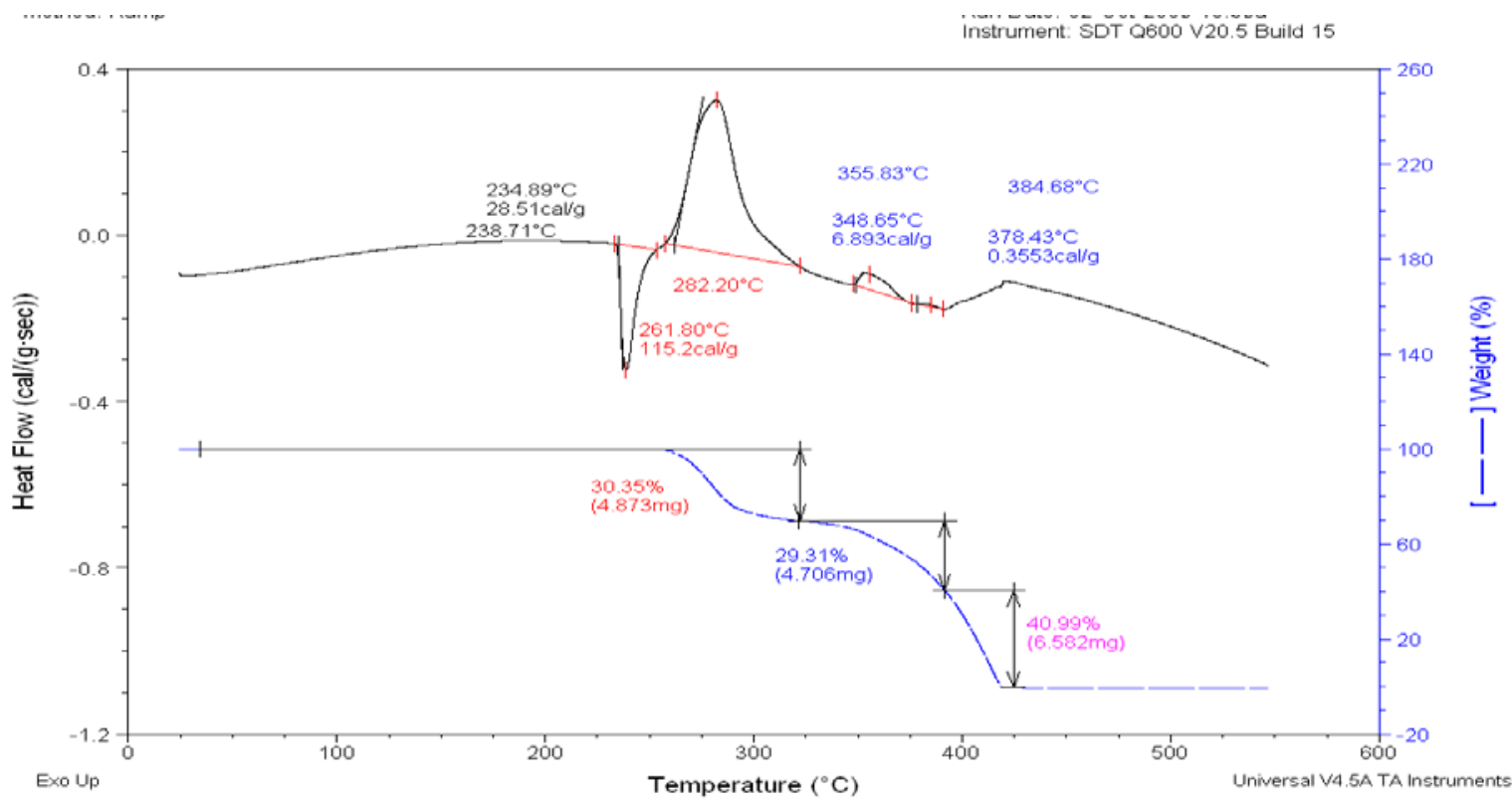

Fig. (4.2) DSC-TGA for AP new source

From Fig. $(4,1)$ and Fig. $(4,2)$ it's clear that there is a slight shifting occurs for endothermic and exothermic peaks of the DSC curves from the old AP to the new one. Also there is some differences in weight loss percentage for both types of AP at the same time and temperature which explain why some changes in burning rate occurred between the old and new AP. This explains why the old source is decomposed at lower temperature than the new one with less amount of weight loss percentage. The shifting of the endothermic and exothermic beaks for the DSC curves of the old and new AP are clear from the results listed in table (4.1).

Table (4.1) Results of thermal study for old and new AP

\begin{tabular}{|c|c|c|c|c|}
\hline \multirow{2}{*}{ \# Sample } & \multicolumn{2}{|c|}{ Endothermic temp ${ }^{\circ} \mathrm{C}$} & \multicolumn{2}{c|}{ Exothermic temp ${ }^{\circ} \mathrm{C}$} \\
\cline { 2 - 5 } & $\begin{array}{c}\text { Onset } \\
\text { temp }\end{array}$ & $\begin{array}{c}\text { Max. } \\
\text { peak temp }\end{array}$ & $\begin{array}{c}\text { Onset } \\
\text { temp }\end{array}$ & $\begin{array}{c}\text { Max. } \\
\text { peak temp }\end{array}$ \\
\hline AP. old source & 234.25 & 237.75 & 255.27 & 268.47 \\
\hline AP. new source. & 234.89 & 238.71 & 261.80 & 282.2 \\
\hline
\end{tabular}

- Results of DSC for the new AP containing different types of burning rate modifiers

- The new AP was mixed with four different BRMS separately which are ferric oxide, cupper chromite, barium ferrite, and tri-calcium phosphate.

- Each one from the four mixtures was tested by the DSC, the onset and maximum peak temperatures for both endothermic and exothermic peaks are listed in tables (4.2- 4.5). The mass of each burning rate modifiers add to one hundred grams of the AP new source (APNS) with the corresponding onset and the maximum peak temperature results are shown in the same tables. 
Table (4.2) Thermal study Results for the mixture of new AP with F.O

\begin{tabular}{|c|c|c|c|c|}
\hline \multirow{2}{*}{$\begin{array}{c}\text { Mass of } \\
\text { FO/g }\end{array}$} & \multicolumn{2}{|c|}{ Endothermic peak } & \multicolumn{2}{c|}{ Exothermic peak } \\
\cline { 2 - 5 } & Onset temp & Max. peak temp & Onset temp & Max. peak temp \\
\hline 0.05 & 241.18 & 251.19 & 291.82 & 307.89 \\
\hline 0.1 & 241.66 & 251.39 & 291.33 & 306.71 \\
\hline 0.3 & 241.52 & 2251.16 & 292.27 & 307.97 \\
\hline 0.4 & 241.50 & 252.21 & 294.19 & 307.65 \\
\hline 0.5 & 241.34 & 249.84 & 291.22 & 307.41 \\
\hline
\end{tabular}

Table (4.3) Results for APNS with T.C.P thermal study

\begin{tabular}{|c|c|c|c|c|}
\hline \multirow{2}{*}{$\begin{array}{c}\text { Mass of } \\
\text { T.C.P/g }\end{array}$} & \multicolumn{2}{|c|}{ Endothermic peak } & \multicolumn{2}{c|}{ Exothermic peak } \\
\cline { 2 - 5 } & Onset temp & Max. peak temp & Onset temp & Max. peak temp \\
\hline 0.05 & 241.9 & 251.52 & 295.12 & 309.56 \\
\hline 0.1 & 241.78 & 251.04 & 295.5 & 310.36 \\
\hline 0.3 & 241.88 & 2251.33 & 294.69 & 310.17 \\
\hline 0.4 & 241.84 & 251.03 & 295.08 & 310.01 \\
\hline 0.5 & 241.81 & 250.34 & 295.29 & 310.49 \\
\hline
\end{tabular}

Table. (4.4) Results for APNS with C.C thermal study

\begin{tabular}{|c|c|c|r|c|}
\hline \multirow{2}{*}{$\begin{array}{c}\text { Mass of } \\
\text { CC/g }\end{array}$} & \multicolumn{2}{|c|}{ Endothermic peak } & \multicolumn{2}{c|}{ Exothermic peak } \\
\cline { 2 - 5 } & Onset temp & Max. peak temp & Onset temp & Max. peak temp \\
\hline 0.5 & 241.69 & 250.09 & 287.06 & 309.4 \\
\hline 1.0 & 241.83 & 249.81 & 290.93 & 305.08 \\
\hline
\end{tabular}

Table (4.5) Results for APNS with B.F thermal study

\begin{tabular}{|c|c|c|c|c|}
\hline Mass of & \multicolumn{2}{|c|}{ Endothermic peak } & \multicolumn{2}{c|}{ Exothermic peak } \\
\cline { 2 - 5 } BF/g & Onset temp & Max. peak temp & Onset temp & Max. peak temp \\
\hline 0.5 & 241.61 & 248.55 & 289.04 & 304.35 \\
\hline 1.0 & 242.49 & 251.67 & 290.55 & 306.49 \\
\hline
\end{tabular}

From the above tables it's obvious that the onset temperature for the endothermic and the exothermic peaks for new AP with all different BRMS are higher than that for old or new AP without modifiers. The onset temperature of the exothermic peaks obtained for the burning rate modifiers CC and BF are lower than those obtained for the BRMS TCP and FO.

\subsection{Characteristics of formulation containing anew AP of different particle size distributions.}

The composition of mix.3, mix.4 and mix.5 where described in table (4.2). In these formulations, the metallic fuel content and the binder content were kept without changing, the particle size distribution of the new AP was altered. The results obtained for the density and stress strain characteristics are listed in table (4.6). 
Table (4.6) Densities and stress strain characteristics for CS RP formulations containing new AP of different particle size distribution

\begin{tabular}{|c|c|c|c|c|c|}
\hline \multirow{2}{*}{ Mix No. } & \multirow{2}{*}{$\begin{array}{c}\text { Density } \\
\text { (g/cm3) }\end{array}$} & \multicolumn{4}{|c|}{ Mechanical Properties } \\
\cline { 3 - 6 } & Stress & Strain \% & Y.M & Shore A \\
\hline $\operatorname{Mix}(3)$ & 1.755 & 5.9 & 35.11 & 38.45 & 56.5 \\
\hline $\operatorname{Mix}(4)$ & 1.745 & 6.6 & 29.44 & 43.65 & 58 \\
\hline $\operatorname{Mix}(5)$ & 1.755 & 7.9 & 32.54 & 38.87 & 57 \\
\hline
\end{tabular}

From table (4.6) the values of the density and shore A obtained from the three compositions were very closed to each other, the highest stress was obtained from the mix.5 and the highest strain was obtained from the mix.3.

The obtained experimental results for ballistic characteristics for the pressure $\mathrm{p}$ and rate of burning r obtained from the two inch motors test are listed in tables (4.7, 4.8 and 4.9). The r-p relation of the three compositions is plotted in figure (4.3).

Table (4.7) Two inch motors test result for mix 3

\begin{tabular}{|c|c|c|c|c|}
\hline \multicolumn{5}{|c|}{ MIX 3 } \\
\hline $\begin{array}{c}\text { Nozzle } \\
\text { Diameter (mm) }\end{array}$ & $\begin{array}{c}\mathrm{P} \\
(\mathrm{bar})\end{array}$ & $\begin{array}{c}\mathrm{r} \\
(\mathrm{mm} / \mathrm{s})\end{array}$ & $\log \mathrm{p}$ & $\log \mathrm{r}$ \\
\hline 8 & 52.87 & 5.85 & 1.723209 & 0.767156 \\
\hline 7.5 & 57.93 & 6.3 & 1.762904 & 0.799341 \\
\hline 7.3 & 63.72 & 6.52 & 1.804276 & 0.814248 \\
\hline
\end{tabular}

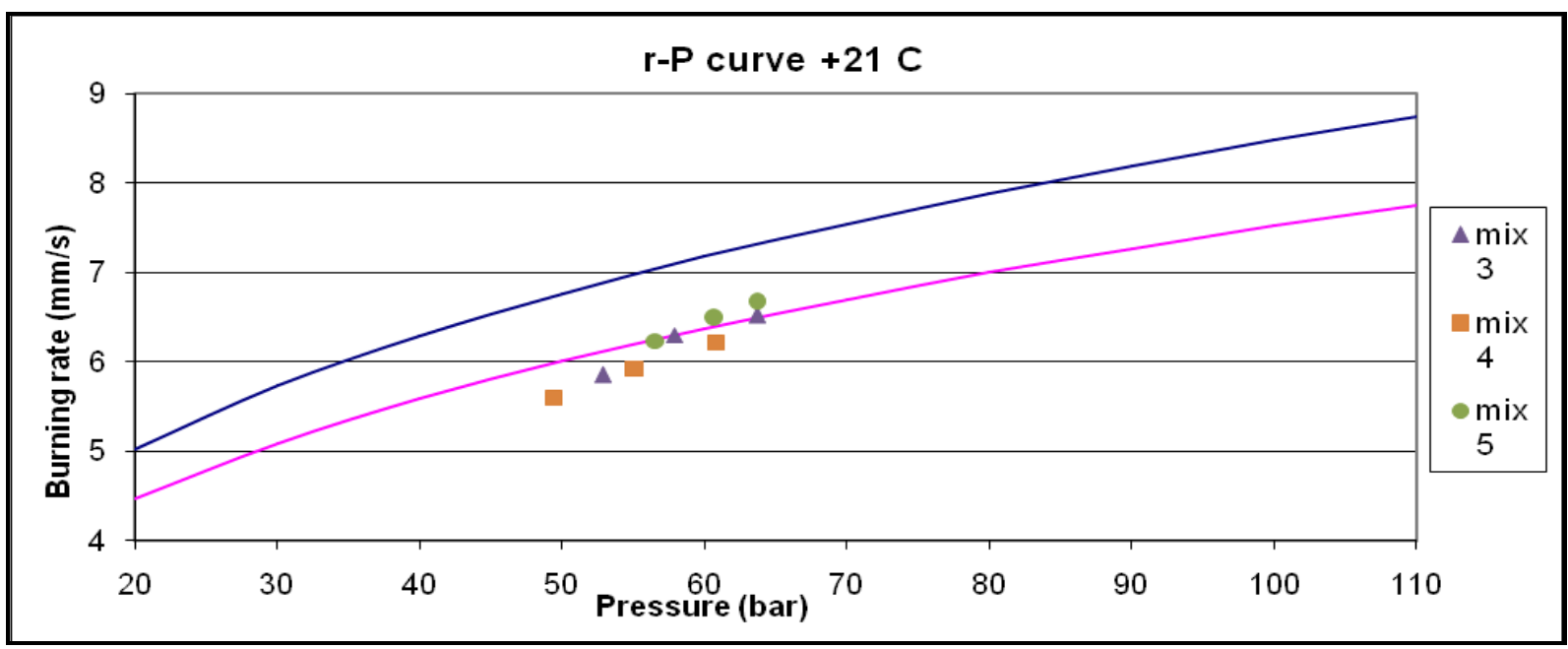

Fig. (4.3) Burning rate behavior of mixtures containing the new AP with different particle size distribution 
Table (4.8) Two inch motors test result for mix 4

\begin{tabular}{|c|c|c|c|c|}
\hline \multicolumn{5}{|c|}{ MIX 4 } \\
\hline $\begin{array}{c}\text { Nozzle } \\
\text { Diameter } \\
(\mathrm{mm})\end{array}$ & $\begin{array}{c}\mathrm{P} \\
(\mathrm{bar})\end{array}$ & $\begin{array}{c}\mathrm{r} \\
(\mathrm{mm} / \mathrm{s})\end{array}$ & $\log \mathrm{p}$ & $\log \mathrm{r}$ \\
\hline 8 & 49.4 & 5.6 & 1.693727 & 0.748188 \\
\hline 7.5 & 55.16 & 5.93 & 1.741624 & 0.773055 \\
\hline 7.3 & 60.83 & 6.22 & 1.784118 & 0.79379 \\
\hline
\end{tabular}

Table (4.9) Two inch motors test result for mix 5

\begin{tabular}{|c|c|c|c|c|}
\hline \multicolumn{5}{|c|}{ MIX 5 } \\
\hline $\begin{array}{c}\text { Nozzle } \\
\text { Diameter } \\
(\mathrm{mm})\end{array}$ & $\begin{array}{c}\mathrm{P} \\
(\mathrm{bar})\end{array}$ & $\begin{array}{c}\mathrm{r} \\
(\mathrm{mm} / \mathrm{s})\end{array}$ & $\log \mathrm{p}$ & $\log \mathrm{r}$ \\
\hline 8 & 63.72 & 6.67 & 1.804276 & 0.824126 \\
\hline 7.5 & 60.73 & 6.49 & 1.783403 & 0.812245 \\
\hline 7.3 & 56.62 & 6.24 & 1.75297 & 0.795185 \\
\hline
\end{tabular}

It's clear that from figure (4.4) that the r-p relations represented by three points for each mix are located outside the accepted zone between the lower and upper limit at temperature $+21^{\circ} \mathrm{C}$.

The three points for mix 5 are just touching the lower accepted limit for r-p relation at $+21^{\circ} \mathrm{C}$. We can come to conclusion that:

a) The burning rate behavior of the three formulations is outside the required aim of the ballistic characteristics for the CSRP.

b) Composition of mix 5 needs little modification to make the points of the R-P relation to be located in the middle of the accepted zone between upper and lower limits of the burning rate behavior at $+21^{\circ} \mathrm{C}$.

\subsection{Mechanical properties of propellant samples}

To facilitate the comparison between the values of the density for all the formulations (mix 1-9), they are represented by columns as shown in figure (4.4)

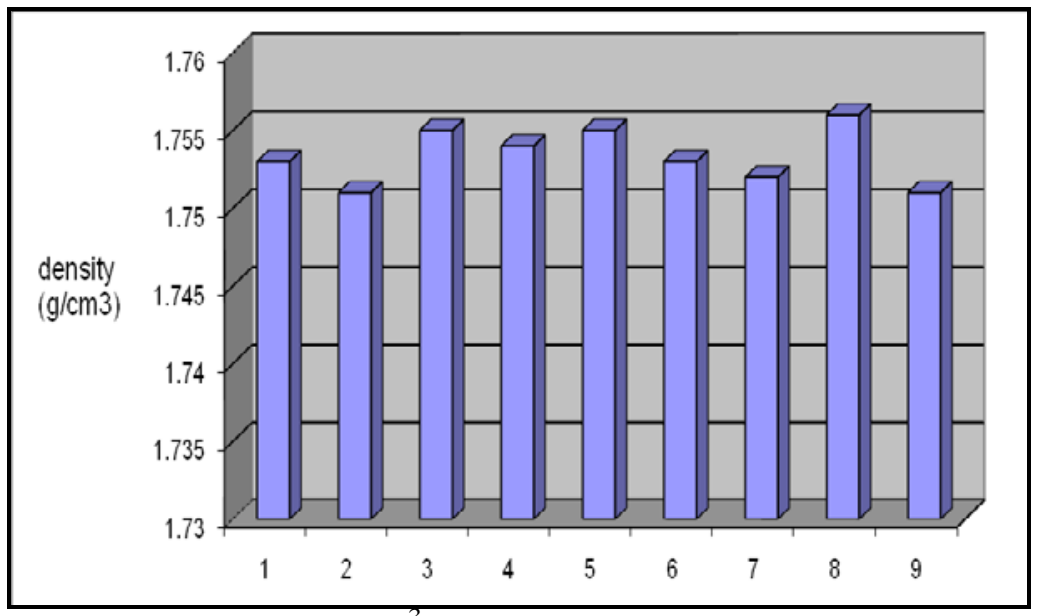

Fig. (4.4) Density (g/cm ${ }^{3}$ ) for all prepared compositions 
From Fig. (4.4)it is clear that allthe samples have approximately same density which means slight amount of BRM didn't change the basic value of the prepared samples density.

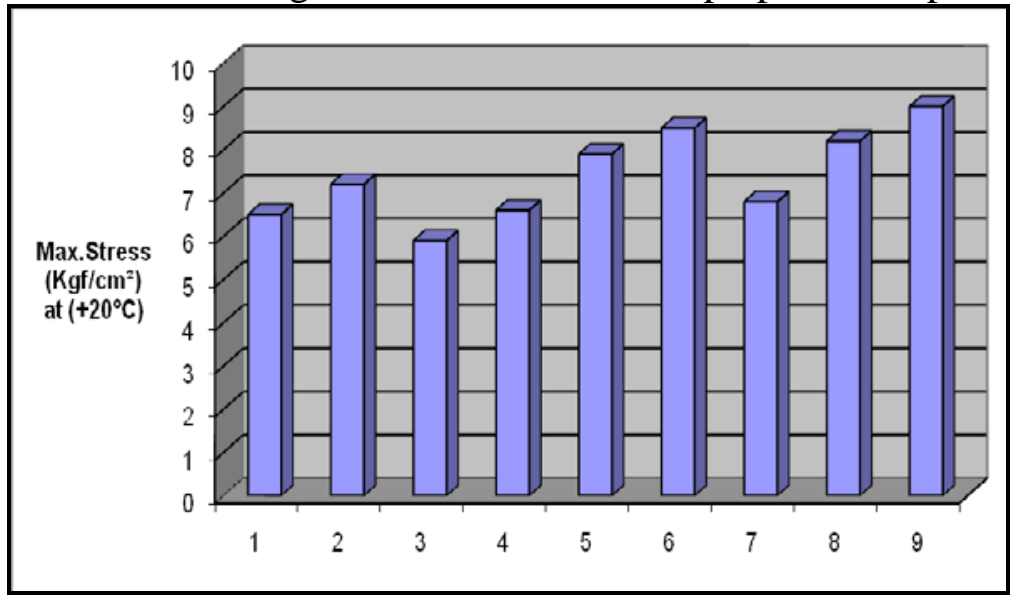

Fig. (4.5) Max Stress $\left(\mathrm{kgf} / \mathrm{cm}^{2}\right)$ for all prepared compositions

The values of maximum stress, maximum strain and young's modulus for all the prepared formulation in this work are represented by columns in figures $(4.5-4.7)$ to facilitate the comparison between those values.

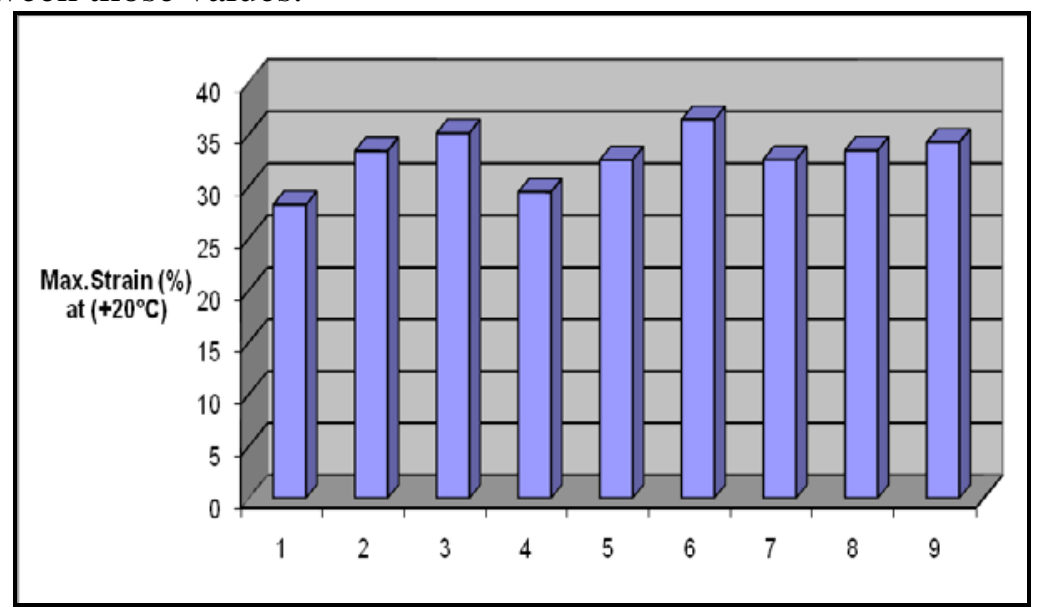

Fig. (4.6) Max Strain \% for all prepared compositions

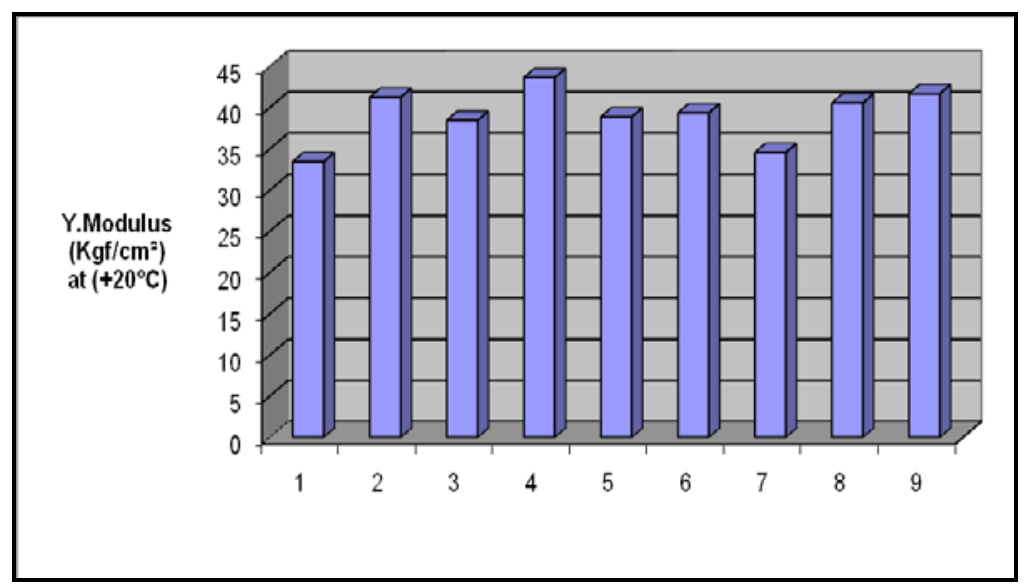

Fig. (4.7) Young Modules $\left(\mathrm{kgf} / \mathrm{cm}^{2}\right)$ for all prepared compositions 
The mechanical properties of all the prepared propellant sample have the recommended margin which indicates that different BRM haven't any obvious effect on the samples mechanical properties and also shows well prepared sample with perfect raw materials.

\subsection{Ballistic properties of composite solid rocket propellant formulations based on new source $A P$ and different burning rate modifiers}

The above mentioned CSRP formulations (mixes 6-9) were tested by using two inch rocket motor to determine the r-p relations employing different nozzles.

The obtained results of r-p relations are listed in table (3.10) also the location of the points which represent those relations between $r$ and $p$ are plotted in figure (3.8).

Table (4.10) two inch motors test results for CSRP compositions containing the new source of AP with different BRMS

\begin{tabular}{|c|c|c|c|c|c|c|c|c|}
\hline \multicolumn{3}{|c|}{ MIX.6. With $\mathrm{Fe}_{2} \mathrm{O}_{3}$} & \multicolumn{3}{c|}{ MIX.7. With C.C } & \multicolumn{2}{c|}{ Mix.8. With B.F } & \multicolumn{2}{c|}{ Mix.9. With TCP } \\
\hline $\begin{array}{c}\text { Nozzle } \\
\text { Diameter } \\
(\mathrm{mm})\end{array}$ & $\begin{array}{c}\mathrm{P} \\
(\mathrm{b})\end{array}$ & $\begin{array}{c}\mathrm{r} \\
(\mathrm{mm} / \mathrm{s})\end{array}$ & $\begin{array}{c}\mathrm{P} \\
(\mathrm{bar})\end{array}$ & $\begin{array}{c}\mathrm{r} \\
(\mathrm{mm} / \mathrm{s})\end{array}$ & $\begin{array}{c}\mathrm{P} \\
(\mathrm{bar})\end{array}$ & $\begin{array}{c}\mathrm{r} \\
(\mathrm{mm} / \mathrm{s})\end{array}$ & $\begin{array}{c}\mathrm{P} \\
(\mathrm{bar})\end{array}$ & $\begin{array}{c}\mathrm{r} \\
(\mathrm{mm} / \mathrm{s})\end{array}$ \\
\hline 8 & 62.69 & 7.55 & 58.78 & 6.41 & 52.03 & 6.66 & 52.85 & 5.84 \\
\hline 7.5 & 86.66 & 8.39 & 58.78 & 6.8 & 65.71 & 7.34 & 60.47 & 6.03 \\
\hline 7 & 96.34 & 8.66 & 58.78 & 6.81 & 75.27 & 7.51 & 68.33 & 6.27 \\
\hline
\end{tabular}

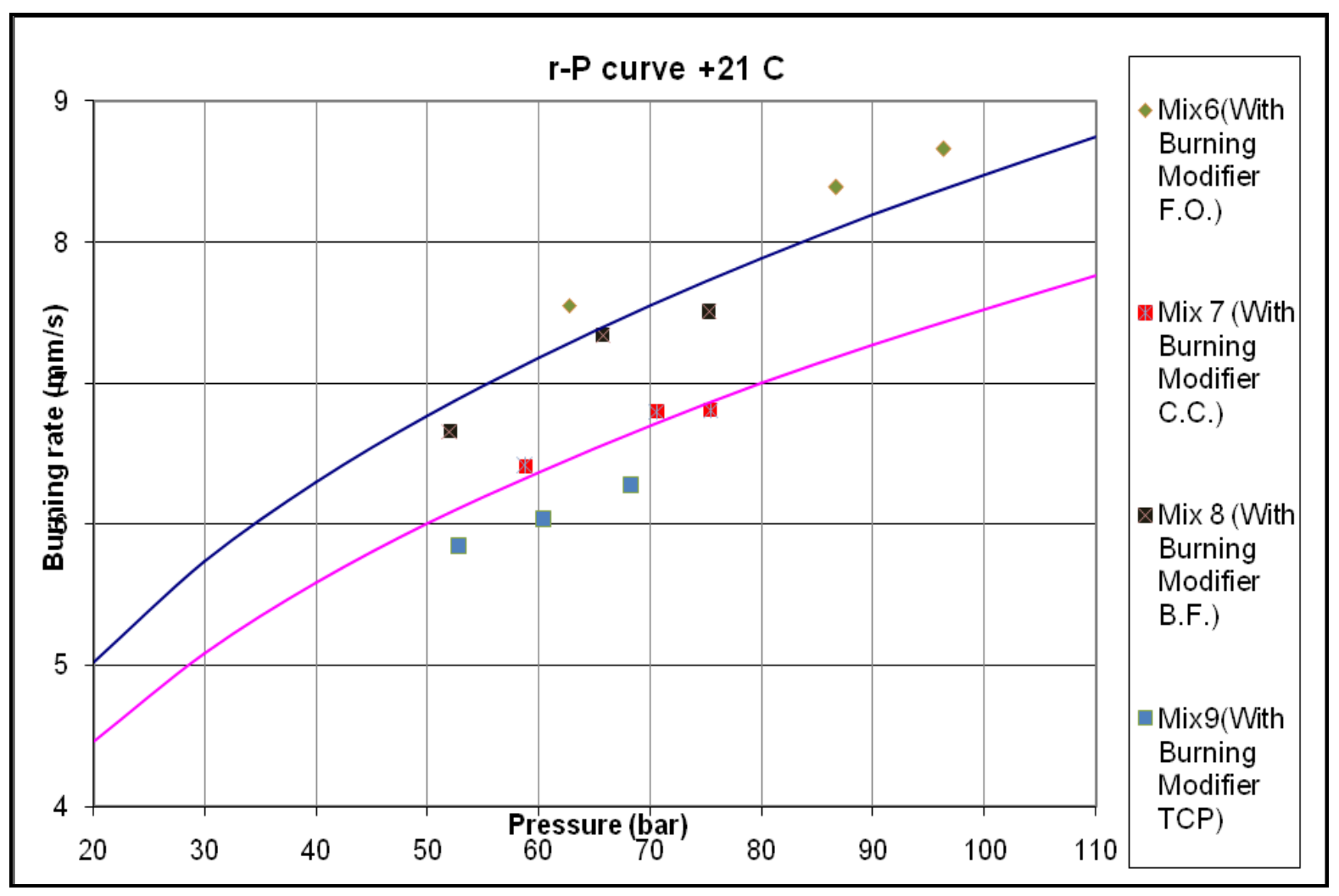

Fig. (4.8) Ballistic behavior for CSRP containing different BRMS with new AP 
From the results in the Table (4.10) and Fig. (4.8), it is clear that the compositions containing copper chromite and ferric oxide (mix 6 and mix 7) are not within the accepted standard lower and upper limit of r-p relation at $+21^{\circ} \mathrm{C}$. The CSRP composition containing Barium ferrite (mix 8) has r-p relation inside the required standard reference domain but very close to the upper accepted r-p limit. It is believe that by lowering the percent of the barium ferrite modifier from $0.06 \%$ to 0.05 or $0.04 \%$ the location of the points of r-p relations should be in the middle of the standard reference domain, CSRP formulation containing TCP (mix 9) does not modify affect the r-p relation and gives the results as sample without BRM, which indicates that TCP works as anti-caking agent only and haven't any effect of increasing the burning rate of CSRP formulations. Figure (4.9) contains the r-p relations for the prepared formulations, mixes $1,2,6,7,8$ and 9 to facilitate the comparison between them at $+21^{\circ} \mathrm{C}$.

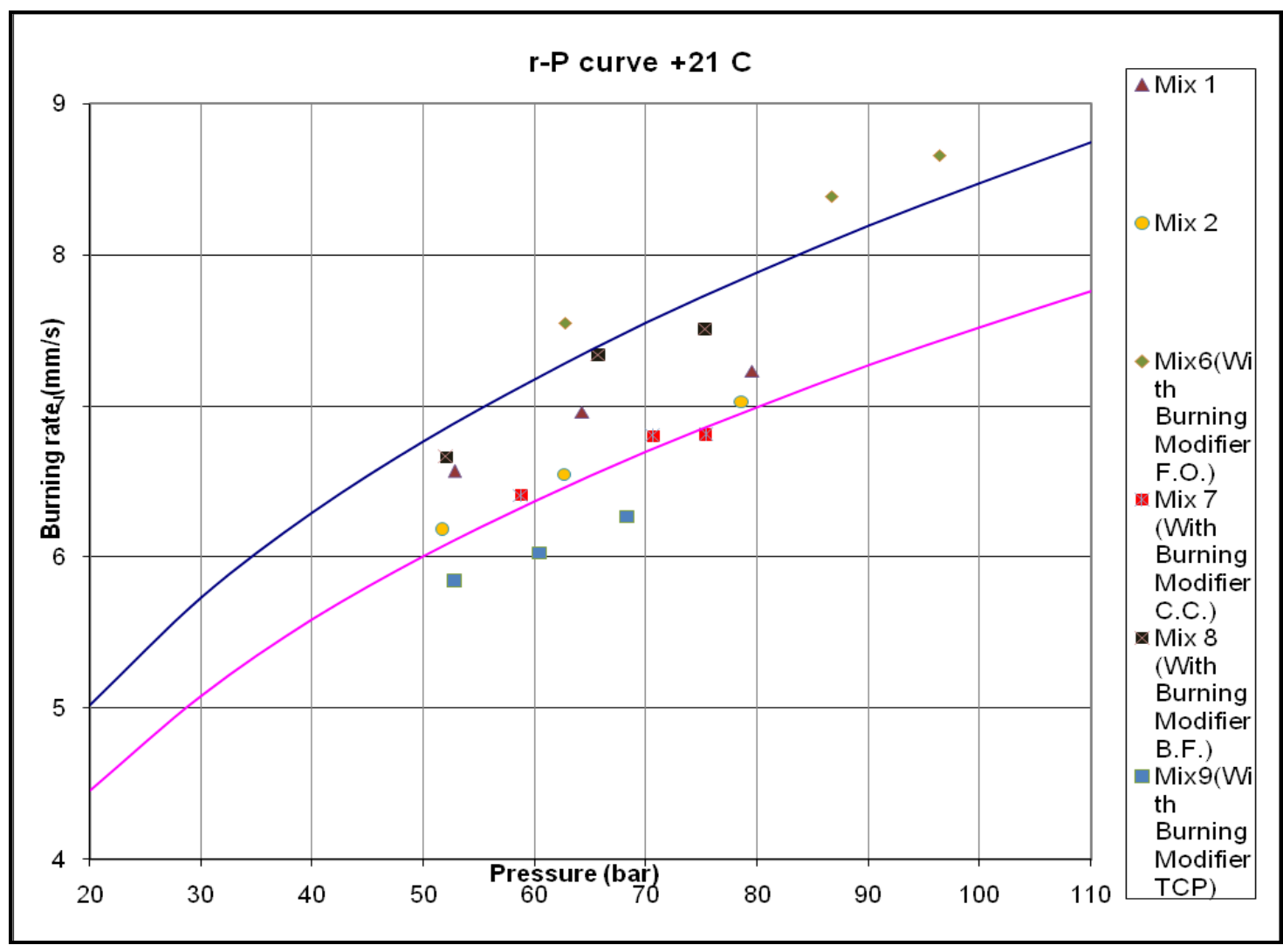

Fig.(4.9) Ballistic behavior for CSRP containing different BRMS also traditional compositions using old and new AP without BRMS

It's obvious from this figure that the composition containing barium ferrite has r-p relation close to that of the standard r-p relation of mix 1. Hence it's recommended to use this modifier in CSRP formulations containing the new AP but with slight decreasing the weight percent of this modifier. The values of the constant (a) and the exponent (n) for the r-p relation:

$$
\mathrm{R}=\mathrm{ap}^{\mathrm{n}}
$$

The obtained values of (a) and (n) for the relation $r=a p^{n}$ of the different CSRP formulations containing the different BRM are listed in table (4.11). 
Table (4.11) Values of $a$ and $n$ for the relation $r=a p^{n}$ of the different CSRP formulations containing the different BRM

\begin{tabular}{|c|c|c|c|c|c|c|c|}
\hline \multicolumn{2}{|c|}{ Mix 6 } & \multicolumn{2}{c|}{ Mix 7 } & \multicolumn{2}{c|}{ Mix 8 } & \multicolumn{2}{c|}{ Mix 9 } \\
\hline $\mathrm{a}$ & 0.320 & $\mathrm{a}$ & 0.335 & $\mathrm{a}$ & 0.275 & $\mathrm{a}$ & 0.275 \\
\hline $\mathrm{n}$ & 1.99 & $\mathrm{n}$ & 1.87 & $\mathrm{n}$ & 1.87 & $\mathrm{n}$ & 1.77 \\
\hline
\end{tabular}

It's obvious from table (3.11) that the values of the constant a and the exponent $\mathrm{n}$ for the recommended CSRP formulation containing barium ferrite modifier are very close from the values of the standard one.

\section{Conclusion}

It was clear that the practical work on laboratory scale will give us more obvious results by Changing in chemical compositions then the results analysis from two test motors leads to use different available burning rate modifiers (Ferric oxide, Cupper Chromites and Barium ferrite) with different particle size with the same weight percentages of exact particle size AP shows the significant effect on the AP activation energy using DSC.

Using different burning rate modifiers with different particle size (CC, BF and FO) with the same weight percentages shows the significant effect on the burning rate behavior. From the previous note that it's shown the BF is the best burning rate modifier could be used to adjust the AP from new source.

There is no obvious difference in mechanical and physical properties due to change the kind or particle size of burning rate modifier.

\section{References}

[1] Davenas A. Solid Rocket Propulsion Technology[M]. New York: Pergamon Press, 1993: 415-437.

[2] Sutton G P. Solid Rocket Propulsion Elements[M]. Sixth Edition. New York: Willy Intersience Publication, 1992: 424.

[3] Hori K, et al. On the Adhesion Between Hydroxy-Terminated Polybutadiene Fuel Binder and Ammonium Perchlorate Performance of Bonding Agents[J]. Propellant, Explosives, Pyrotechnics , 1985, 176-180.

[4] Rocket propellant Hand Book. Boris Kit and Douglas S. EVERED,1960.

[5] MohmedA.Sadek ,.Saeed Hasaninand.Hosam El SaedMostafa "InvestegationAnd Analysis Of The Role Of Energetic Reinforcements In Rocket Propellants” MTC ,Cairo,1996.

[6] Ph.D thesis by WAEL Mohamed Ahmed Abdel Wareth“An Investigation Methodology On The Performance Parameters Prediction for (butalites) Composite Solid Propellants”Beihang University, China 2012.

[7] GEORGEP. Sutton. Rocket Propulsion Elements[M]. Sixth Edition, New York: John Wiley \& Sons, Inc., 1992, Chapter 13.

[8] ALAIN Davenas. Solid Rocket Propulsion Technology [M].Oxford: Pergamon Press,1993, Chapter 4.

[9] MAKOTOKohga. Burning rate characteristics of ammonium perchlorate based. Composite propellant using bimodal ammonium perchlorate[J].Journal of Propulsion and Power, 2008, 24 (3): 499-506 
[10] ABDEL-WARETH W. M. Study of the Combustion Behavior of the Low Oxygen Content Composite Solid Propellants [D].Cairo University, Faculty of Engineering, Cairo, Egypt, M. Sc. Thesis, 2006.

[11] A.Al-Harthi and A. Williams 1998, Effect of fuel binder and oxidizer particle diameter on the combustion of ammonium perchlorate based propellants.

[12] Frederick M. Gallant ${ }^{\mathrm{a},{ }^{*}}$; Suzanne .E. Pricktt ${ }^{\mathrm{a}}$, Mario Cesarec ${ }^{\mathrm{a}}$, Hugh A. Bruck ${ }^{\mathrm{a}}$ 2007, Ingredient and processing effects on the Burning rate of Composite rocket propellants utilizing a reduced - run mixture- process experiment design.

[13] M. M. Mench, C. L. Yeh, K. K. Kuo, Propellant Burning Rate Enhancement on Thermal Behaviour of Ultra-Fine Alumi-nium Powders (ALEX), $29^{\text {th }}$ Int.Annual Conference of ICT, Karlsruhe, Germany, June 30 - July 3, 1998, p. 30/1.

[14] M. M. Telkar, C. V. Rode, R. V. Choudhary, S. S. Joshi, A. M. Nalawade, ShapeControlled Preparation and Catalytic Ac- tivity of Metal Nanoparticles for Hydrogenation of 2-Butyne-1,4-diol and Styrene Oxide, Appl. Catal, A 2004, 273, 11. 